\title{
ERRATUM
}

\section{Effective reversal of a transformed phenotype by retrovirus-mediated transfer of a ribozyme directed against mutant $\mathrm{N}$-ras}

M Scherr et al

In the above paper Figures 5 and 6 were misleading due to the identical representation of two different sets of data. The correct representations of these figures is shown below.

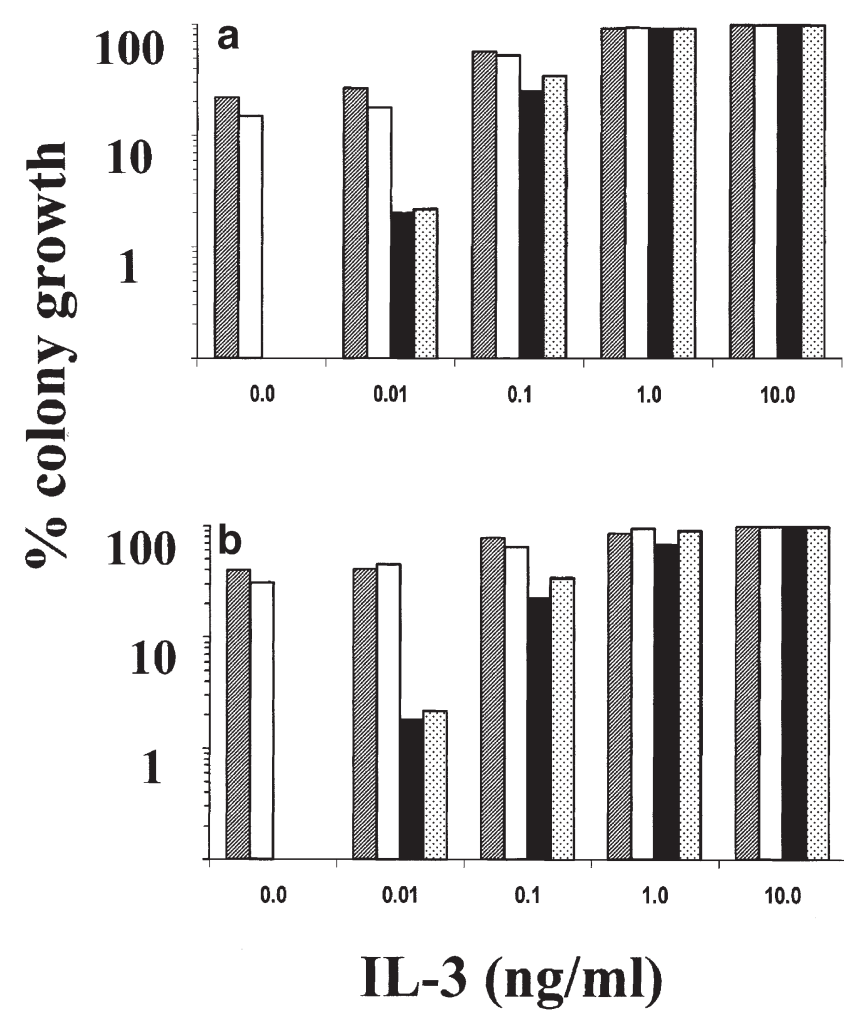

Figure 5 Restoration of IL-3-dependent colony growth in $\mathrm{N}^{13}$-ras-transformed TF-1 cells after transduction with $p$ Babe-REC, but not with $p$ BabeNRE. Cells from $N^{13}$-ras transformed clones $5 / 1(a)$ and $5 / 2(b)$ were infected with a retrovirus carrying the active ribozyme, $p B a b e-R E C$ (black bars), the inactive ribozyme, pBabe-NRE (white bars) or the vector alone, pBabe-puro (hatched bars) and compared with control TF-1 cells (dotted bars) in their colony growth to stimulation with IL-3. The number of colonies obtained in methylcellulose after plating $10^{3}$ TF-1 cells in the presence of IL-3 $(10 \mathrm{ng} / \mathrm{ml})$ was defined as $100 \%$ colony growth.

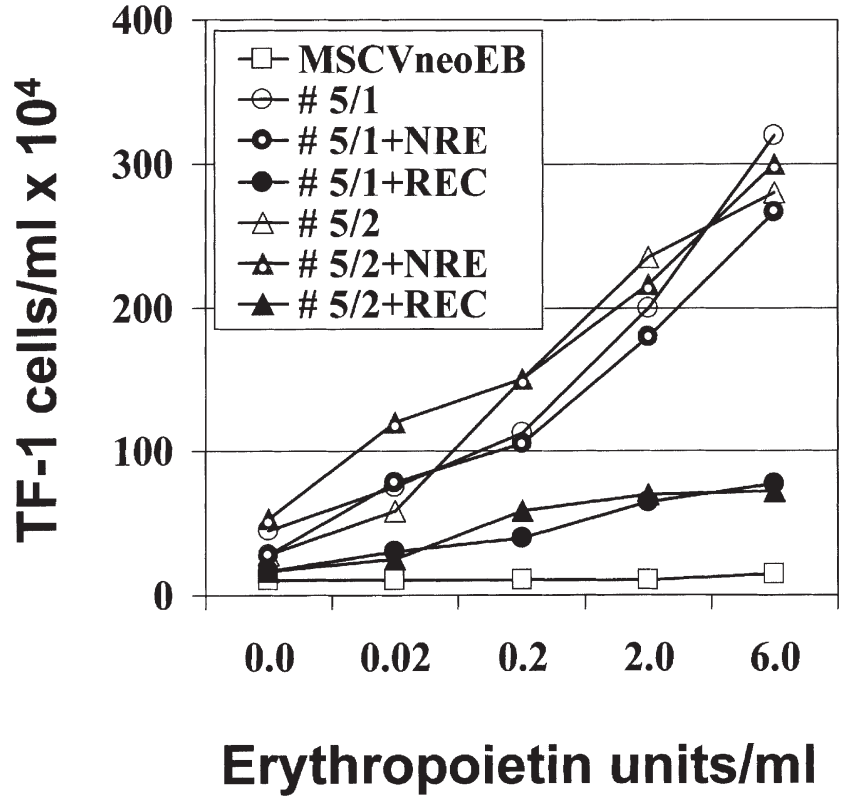

Figure 6 Ribozyme-mediated reversion of Epo-induced growth in $N^{13}$-ras transformed TF-1 cells. Clones 5/1 and 5/2 expressing mutant $N^{13}$-ras were transduced with pBabe-puro (\#5/1 and \#5/2), the active ribozyme, pBabe-REC (\#5/1+REC and \#5/2+REC), or a nonsense ribozyme, $p$ BabeNRE (\#5/1+NRE and \#5/2+NRE) and compared in their Epo-induced proliferation with control TF-1 cells transduced with MSCV neoEB. Cells were plated at $10^{4}$ cells $/ \mathrm{ml}$ in triplicate wells with different concentrations of Epo and counted after 7 days. The mean values were calculated from six independent experiments. 